\title{
Type 2 Vague Events and Their Applications
}

\section{Houju Hori Jr. Ph.D}

Chief in Nara Community, Tsubakikishi Shrine, Japan

Email: uemura0742@yahoo.co.jp

\section{Article History}

Received: December 15, 2020

Revised: January 20, 2021

Accepted: January 22, 2021

Published: January 24, 2021

\begin{abstract}
[1] discovered a mapping formula for Type 1 Vague events, and presented an alternative problem as an example of its application. Since it is well known that the alternative problem results in sequential Bayesian inference, the subsequent research flow is to make the mapping formula multidimensional, to derive the Markov (decision) process by introducing the concept of time, and so on. Furthermore, the stochastic differential equation from which it is derived was formulated. [2] This paper refers to Type 2 Vague events based on the secondary mapping formula. This quadratic mapping formula gives a certain rotation to a non-mapping function by transforming it with a relationship between the two mapping functions. Furthermore, here we refer to the derivation of the Type 2 Vague Markov process and the initial and stop conditions for its rotation.
\end{abstract}

Keywords: Vague; Events; Application; Mapping formula.

\section{Introduction}

Yoshiki [1] discovered the official mapping. It is sometimes called Vague because it is distinguished from the fuzzy logic of The Day (1965). Therefore, our study was named Vague Sets and Theory [2]. The day's fuzzy deals with vertical ambiguity, while our Vague deals with horizontal ambiguity. Also, The Day's modeling is conceptually very close to the interval modeling of subjective Bayesian theory, and the rotation based on our quadratic mapping formula is very related to factor analysis or independent component analysis [3]. Our study image is eye. From our moving eye, we can obtain our feeling on our decision. As our feeling is some factor in this case, it is the vague factor. Therefore, our study can analysis this vague factor.

\section{Type 2 (fuzzy) Markov Process}

Yoshiki [1], obtained the type 1 mapping formula (1) on some function $\mathrm{f}(\mathrm{x})$ by $\mathrm{g} 1(\mathrm{x})$.

[1] defined the formula for mapping a function with Eq. (1). However, here, an alternative problem was shown as an application example. Later, it is shown to be a theorem [2].

$S U P_{y=f(x)} \quad g_{1}(x)=g_{1}\left(f^{-1}(y)\right)$

Next, [3] formulated the formula for the secondary mapping as in equation (2).

$S U P_{y=f(x)} \quad g_{2}(Z)=g_{2}\left(g_{1}^{-1}\left(f^{-1}(y)\right)\right)$

$Z=g_{1}\left(f^{-1}(y)\right)$

Here, in Eq. (2), it is the formula of the quadratic mapping that maps Eq. (1) again with. A notable property in the quadratic mapping formula is that when the mapping functions are equivalent as in Eq. (3), they are inverted 180 degrees. This indicates that it is a kind of main factor analysis. Here, in the main factor analysis, 180 degree rotation requires two rotations every 90 degrees. However, note that the formula for the secondary map is flipped 180 degrees in a single rotation. $g_{2}(x)$

$g_{1}(\cdot)=g_{2}(\cdot)$ のとき $x=f^{-1}(y)$

Next, assuming that the transition matrix is L, the Markov process is formulated as follows [4]. $D_{t}$

$D_{t}=L\left(t, x_{t}\right)$

Finally, the type 1 Markov process that introduced the concept of Vague is derived by equation (5), and the type 2 Markov process is derived by equation (6).

$$
\begin{aligned}
& F_{t}=L^{-1}\left(t, g_{1}\left(x_{t}\right)\right) \\
& F_{F_{t}}=\underset{\left\{y_{t}=L^{-1}\left(t, g_{1}\left(f\left(x_{t}\right)\right)\right)\right.}{S U P} L^{-1}\left(t, g_{2}\left(x_{t}\right)\right) \\
= & L^{-1}\left(t, L^{-1}\left(t, g_{2}\left(g_{1}^{-1}\left(f^{-1}\left(y_{t}\right)\right)\right)\right.\right.
\end{aligned}
$$




\section{Initial Condition and Stop Condition}

The initial and stop conditions for a normal Markov process are shown in Yoichiro [4]. Since we are dealing with horizontal ambiguity, we introduce the concept of two-dimensional Possibility Theory [5]. The initial conditions and stop conditions are shown in Eqs. (7) and (8), respectively.

(1) $\left(F_{10 t}, F_{20 t}\right)=\left(Z_{10 t}, Z_{20 t}\right)$

(2) $\operatorname{POS}\left(\left(F_{1 t}, F_{2 t}\right) \geqq\left(Z_{1 t}, Z_{2 t}\right) \mid x_{0}\right) \leqq \operatorname{POS}\left(\left(D F_{1} x_{0}, D F_{2} x_{0}\right) \geqq\left(D Z_{1} x_{0}, D Z_{2} x_{0}\right)\right)$

(3) $\left.\operatorname{NES}\left(\left(F_{1 t}, F_{2 t}\right) \geqq\left(Z_{1 t}, Z_{2 t}\right) \mid x_{0}\right)\right) \geqq N E S\left(\left(D F_{1 t} x_{0}, D F_{2 t} x_{0}\right) \geqq\left(D Z_{1 t} x_{0}, D Z_{2 t} x_{0}\right)\right)$ ここで $\left(\mathrm{D} F_{1 t} x_{0}, D F_{2 t} x_{0}\right)=\left(D X_{1 t}, D Z_{2 t}\right)$

$* F_{10}(\cdot)_{t}=F_{20}(\cdot)_{t}$

(1) $F_{t i 0}=Z_{t i 0} \quad(i=1.2)$

(2) $\operatorname{POS}\left(F_{i t} \geqq Z_{i t} \mid x_{i 0}\right) \leqq P O S\left(D F_{x i 0} \geqq D Z_{x i 0}\right) \quad(i=1,2)$

(3) $N E S\left(F_{i t} \geqq Z_{i t} \mid x_{i 0}\right) \geqq N E S\left(D F x_{i 0} \geqq D Z x_{i 0}\right) \quad(i=1,2)$

ここで、DF $x_{i 0}=D Z x_{i o} \quad(i=1,2)$

Here, represents two vague events, and a two-dimensional possibility theory is applied. If the mapping functions have the same value, they are inverted 180 degrees, and the initial condition and the stop condition are inverted. Note that in this case, the Vague event is also one. $F_{i 0 t} D F_{i 0 t}(i=1,2)$

(1) $\left(F_{1 t 0}, F_{2 t 0}\right)=\left(Z_{1 t 0}, Z_{2 t 0}\right)$

(2) $\operatorname{POS}\left(\left(F_{1 t 0}, F_{2 t 0}\right) \geqq\left(Z_{1 t}, Z_{2 t}\right)\right) \leqq \operatorname{POS}\left(\left(D F_{10}, D F_{20}\right) \geqq\left(D Z_{10}, D Z_{20}\right)\right)$

(3) $N E S\left(\left(F_{1 t}, F_{2 t}\right) \geqq\left(Z_{1 t}, Z_{2 t}\right)\right) \geqq N E S\left(\left(D F_{10}, D F_{20}\right) \geqq\left(D Z_{10}, D Z_{20}\right)\right)$

ここで $\left(D F_{10}, D F_{20}\right)=\left(D Z_{10}, D Z_{20}\right)$

$* F_{10}(\cdot)_{t}=F_{20}(\cdot)_{t}$

(1) $F_{t i 0}=Z_{t i 0}(i=1,2)$

(2) $\operatorname{POS}\left(F_{i t} \geqq Z_{i t}\right) \leqq P O S\left(D F_{i 0} \geqq D Z_{i 0}\right)(i=1,2)$

(3) $\operatorname{NES}\left(F_{i t} \geqq Z_{i t}\right) \geqq N E S\left(D F_{i 0} \geqq D Z_{i 0}\right)(i=1,2)$

ここで $D F_{i 0}=D Z_{i 0}$

\section{Conclusion}

In this paper, we mention the type 2 Markov process and derive the initial condition and the stop condition from the two-dimensional possibility theory. A future task is to formulate a stochastic differential equation that derives the formula for the quadratic mapping. Finally, the quadratic mapping formula can be regarded as a multidimensional nonlinear factor analysis and is closely related to the field of artificial intelligence.

\section{References}

[1] Yoshiki, U., 1991. "Decision making in fuzzy events." Journal of the Japanese Fuzzy Society, vol. 3, pp. 123-130.

[2] Hori, H., Jr. Kazuhisa, T., and Yukio, M., 2019. "Complex Markov decision process." Journal of Fuzzy Mathematics, vol. 27.

[3] Yoshiki, H., 2020. "Application of extended principles based on or logic to symbolic systems." Intelligent Systems Symposium of the Society of Instrument and Control Engineers (Nagoya).

[4] Yoichiro, T., 2011. "Kiyoshi Ito's Mathematics, Nihon Hyoronsha."

[5] Dubois, D. and Parade, H., 1988. Possibility theory. Plenum Press. 